\title{
Vitamin K-Dependent Carboxylation in the Developing Rat: Evidence for a Similar Mechanism of Action of Warfarin in Fetal and Adult Livers
}

\author{
REIDAR WALLIN \\ Rheumatology, Department of Medicine, The Bowman Gray School of Medicine, Winston-Salem, \\ North Carolina 27103
}

\begin{abstract}
Our report presents data on maturation of the vitamin K-dependent carboxylation system in fetal and neonatal rat livers. This system which converts precursors of clotting factors II, VII, IX, X, protein S, and protein C to $\gamma$-carboxylated proteins exhibited low $\gamma$-carboxylation activity before birth. However, around the time of birth there was a sudden increase in all enzyme activities associated with the vitamin $\mathrm{K}$-dependent carboxylation system. In 2-d neonatal rats these activities dropped to levels that were measured in fetal livers whereupon the activities had risen to adult levels in 7-d neonatal rats. However, the activities of the two pathways that provide the carboxylase with reduced vitamin $\mathrm{KH}_{2}$ cofactor were never as high as that measured in maternal livers. It appeared that the pathway which is insensitive to coumarin anticoagulant drugs matures later than the coumarin drug-sensitive pathway. This conclusion is supported by the finding of a late appearance in development of the vitamin K-reducing enzyme DT-diaphorase. Warfarin, when administered to the mother, affected the fetal livers at all stages of development studied (d 16-21). This was clearly demonstrated by vitamin K-dependent ${ }^{14} \mathrm{C}$-labeling of a $70-\mathrm{kD}$ liver protein that has been shown previously to be a marker for the effect of this drug on the liver. The data demonstrate a similar mechanism of action of warfarin in fetal and neonatal rat livers and an ongoing maturation process of the vitamin $K$ dependent carboxylation system in these rats. (Pediatr Res 26: 370-376, 1989)
\end{abstract}

\section{Abbreviations}

Vitamin $\mathrm{K}_{1} \mathrm{H}_{2}$, the fully reduced hydroquinone form of vitamin $\mathbf{K}_{1}$

Carboxylase activity, the activity of the enzyme that carries out $\gamma$-carboxylation

DTT, dithiothreitol

It is well documented that premature infants and infants at term are born with reduced levels of many of the essential protein factors of the hemostatic system $(1,2)$. Among these are the vitamin $\mathrm{K}$-dependent clotting factors $(2,3)$. At term, blood concentrations of these factors are about $30-60 \%$ of their con-

Received March 16, 1989; accepted May 26, 1989.

Correspondence and reprint requests Dr. Reidar Wallin Rheumatology, Department of Medicine, The Bowman Gray School of Medicine, 300 South Hawthorne Road, Winston-Salem, NC 27103.

Supported by National Institutes of Health Grant HL 42650. centrations in adult blood $(2,4)$. The low concentrations are found in premature infants where bleeding problems are more frequent and often more severe (5). Plasma concentrations of the vitamin $\mathrm{K}$-dependent clotting factors have been shown to be dependent on gestational age (6) which has raised the question of whether the low concentrations found in the newborn would result from an immature system that produces these proteins.

Kisker et al. (7) have shown recently that changes in the prothrombin antigen and activity levels in blood obtained from fetal lambs at various gestational ages are paralleled by changes in the levels of prothrombin messenger RNA present in liver. Similar results were reported by Hassan et al. (8) when they extracted RNA from fetal liver obtained at abortion in the first trimester of human pregnancy. Indeed, vitamin K-dependent clotting factor production by the liver is dependent upon available mRNA and protein synthesis. However synthesis of these proteins are, in addition, dependent on a vitamin K-dependent carboxylation system that modifies the proteins postribosomally (9) to convert them to the mature $\gamma$-carboxylated $\mathrm{Ca}^{++}$binding proteins (10). This system harbors several enzymes which are necessary for vitamin K-dependent clotting factor production by the liver (11).

The clotting factors are $\gamma$-carboxylated by the vitamin $\mathrm{K}$ dependent carboxylase that uses reduced vitamin $\mathrm{K}_{1}$ hydroquinone as cofactor for the reaction (11). In the liver, where vitamin $\mathrm{K}_{1}$ is received as the quinone, the quinone is reduced to the active cofactor by enzymes belonging to two independent reduction pathways. These are: 1 ) pathway I, a pathway catalyzed by vitamin $\mathrm{K}$ epoxide reductase, an enzyme that is highly sensitive to inhibition by coumarin anticoagulant drugs; 2) pathway II, a pathway catalyzed by pyridine nucleotide-dependent enzymes that are less sensitive to inhibition by these drugs (11). Warfarin, one of the coumarin drugs, has been shown to inhibit pathway I irreversibly (12). Pathway II mediates the antidotal effect of vitamin $\mathrm{K}_{1}$ in overcoming poisoning by coumarin anticoagulant drugs (13). This system for vitamin $\mathrm{K}$ function and vitamin $\mathrm{K}$ metabolism has been shown to be similar in rats and humans (11).

In our study we have investigated in fetal and neonatal rat livers the normal events leading to maturation of the vitamin $\mathrm{K}$ dependent carboxylation system. Our data demonstrate an ongoing maturation process of the system in fetal and neonatal rats. Significant changes in the system were found around birth.

\section{MATERIALS AND METHODS}

Animals. Time-pregnant Sprague-Dawley rats were purchased from Zivic-Miller Laboratories, Inc. (Zelienople, PA). Rats were divided into groups according to gestational age and five rats 
were used in each group. All pregnant rats and neonatal rats treated with warfarin were given $30 \mathrm{mg} / \mathrm{kg}$ of the drug intraperitoneally in saline $24 \mathrm{~h}$ before death. Control animals received the same quantity of saline. Warfarin-treated and control animals were killed on d 16, 17, 18, 19, and 20 before birth, at birth (d 21) and on $\mathrm{d} 2$ and 7 after birth. Before death by decapitation all rats were anesthetized with pentobarbital.

Preparation of Liver Microsomes. Livers from fetal rats, neonatal rats, and mothers in the various groups were each pooled separately and homogenized in $250 \mathrm{mM}$ sucrose, $25 \mathrm{mM}$ imidazole, $\mathrm{pH} 7.2$, containing $5 \mathrm{mM}$ benzamidine (buffer $\mathrm{A}$ ) as described (11). The homogenate was centrifuged twice at 10000 $\times g$ for $10 \mathrm{~min}$ and then at $100000 \times g$ for $60 \mathrm{~min}$ to obtain a microsomal pellet. The pellets from the $100000 \times g$ spin were resuspended in buffer $\mathrm{A}$ and pelleted a second time by centrifugation at $100000 \times g$ for $60 \mathrm{~min}$. The final microsomal pellets were stored in liquid $\mathrm{N}_{2}$.

Measurements of Enzyme Activities. Vitamin K-dependent carboxylase. Vitamin K-dependent carboxylase activity was measured as ${ }^{14} \mathrm{CO}_{2}$ incorporation into the synthetic peptide substrate Phe-Leu-Glu-Glu-Leu (peptide carboxylation) and also as ${ }^{14} \mathrm{CO}_{2}$ incorporation into endogenous microsomal protein substrates (protein carboxylation) (14). All activity measurements were carried out in buffer B $(25 \mathrm{mM}$ imidazole, $5 \mathrm{mM}$ benzamidine, $0.5 \%$ 3-[(3-cholamidopropyl)-dimethylammonio]1-propanesulfonate, $\mathrm{pH} 7.2$ ) in the presence of $1 \mathrm{mM} \mathrm{MnCl}_{2}$ and $5 \mathrm{mM}$ DTT as described (11). Incubations with chemically reduced vitamin $\mathrm{K}_{1} \mathrm{H}_{2}$ contained $100 \mu \mathrm{g} / \mathrm{mL}$ of the reduced vitamin. Carboxylase activity supported by pathway I and II was measured as follows. Pathway I supported: incubations contained $100 \mu \mathrm{g} / \mathrm{mL}$ of vitamin $\mathrm{K}_{1}$ quinone. Pathway II supported: incubations contained $100 \mu \mathrm{g} / \mathrm{mL}$ of vitamin $\mathrm{K}_{1}$ quinone, $2 \mathrm{mM}$ $\mathrm{NADH}$ and $50 \mu \mathrm{M}$ warfarin for inhibition of pathway $\mathrm{I}$.

Vitamin $K$ epoxide reductase. Vitamin $\mathrm{K}$ epoxide reductase activity was measured in microsomes resuspended in buffer $A$. Incubations contained $10 \mu \mathrm{M}$ of vitamin $\mathrm{K}_{1} 2,3$ epoxide and 5 mM DTT. Activity was measured as \% conversion of the epoxide to vitamin $K_{1}$ quinone using an HPLC system for separation of the two components. The assay system is described in detail elsewhere (9).

DT diaphorase. DT diaphorase (E.C. 1.6.99.2) activity was measured in lung and liver cytosol as reduction by NADH of the dye 2,6-dichlorophenol indophenol. The assay system is described in detail elsewhere (15).

Prothrombin Precursor. The microsomal concentration of the prothrombin precursor was measured by immunodot blotting as described by Reiderer et al. (16). For this assay the microsomal pellet was dissolved in $250 \mathrm{mM}$ sucrose, $25 \mathrm{mM}$ imidazole, 0.5 $\mathrm{M} \mathrm{KCl}, 1.5 \%$ Triton X-100, pH 7.2. Aliquots of $1-2 \mu \mathrm{L}$ were spotted on nitrocellulose membranes that were reacted subsequently with rat prothrombin antibodies and ${ }^{125} \mathrm{I}$-protein $\mathrm{A}$ as described (17). Rat plasma containing $1.5 \%$ Triton X-100 and $0.5 \mathrm{M} \mathrm{KCl}$ was used as standard for estimation of the prothrombin precursor concentration. A plasma concentration of $0.1 \mathrm{mg} /$ $\mathrm{mL}$ was assumed for prothrombin. Rabbit antiserum against rat prothrombin was obtained as described (17).

Plasma Prothrombin Time. Blood was drawn from the vena cava into $2.85 \%$ sodium citrate (blood/citrate ratio; $9: 1 \mathrm{vol} / \mathrm{vol}$ ). Blood samples from all five rats within each group were pooled. Prothrombin time was determined with rabbit brain thromboplastin as described in the instruction manual from the supplier (Sigma Chemical Co., St. Louis, MO).

${ }^{14} \mathrm{C}$-Labeling of Microsomal Carboxylase Substrates. Endogenous protein substrates for the carboxylase in microsomes from fetal and adult rat livers were ${ }^{14} \mathrm{C}$-labeled according to a protocol described in (17). Briefly, microsomes suspended in buffer B were incubated for $30 \mathrm{~min}$ at $25^{\circ} \mathrm{C}$ in the presence of $1 \mathrm{mM}$ $\mathrm{MnCl}_{2}, 5 \mathrm{mM}$ DTT, $40 \mu \mathrm{Ci} / \mathrm{mL}$ of $\mathrm{H}^{14} \mathrm{CO}_{3}^{-}$and $100 \mu \mathrm{g} / \mathrm{mL}$ of reduced vitamin $\mathrm{K}_{1} \mathrm{H}_{2}$. The incubation mixture was gel filtrated on Sephadex G-25 in $10 \mathrm{mM} \mathrm{NH}_{4} \mathrm{HCO}_{3}, 5 \mathrm{mM}$ benzamidine, and the void volume fraction lyophilized and subjected to SDSPAGE.

SDS-PAGE and Fluorography. SDS-PAGE was carried out according to Laemmli (18) in $10 \%$ reducing gels. Before electrophoresis, all samples were boiled for $2 \mathrm{~min}$ in the presence of $5 \%$ mercaptoethanol and $2 \%$ SDS. ${ }^{14} \mathrm{C}$-methylated standard proteins (Amersham Corp., Arlington Heights, IL) were used for $\mathrm{M}_{\mathrm{r}}$ determinations. Gels selected for fluorography were fixed over night in $10 \%$ trichloroacetic acid, $10 \%$ acetic acid, $25 \%$ methanol, and treated with EN ${ }^{3} \mathrm{HANCE}$ (New England Nuclear, Boston, MA) for $1 \mathrm{~h}$. The dried gel was exposed to Kodak X-Omat XAR-5 film (Eastman Kodak, Rochester, NY) at $-70^{\circ} \mathrm{C}$ for 4 weeks.

Materials. Vitamin $\mathrm{K}_{1}$ used for preparation of chemically reduced vitamin $\mathrm{K}_{1} \mathrm{H}_{2}$ was from Sigma. The vitamin was reduced with dithionite as described by Sadowski et al. (19). Vitamin $K_{1}$ quinone used in the assay system was the commercial preparation Aquamephyton obtained from Merck Sharp and Dohme, West Point, PA. $\mathrm{NaH}^{14} \mathrm{CO}_{3}(60 \mathrm{mCi} / \mathrm{mmol})$ and ${ }^{125} \mathrm{I}$-Protein $\mathrm{A}(>30$ $\mathrm{mCi} / \mathrm{mg}$ ) were from Amersham.

The pentapeptide Phe-Leu-Glu-Glu-Leu was from Vega Fox Biochemicals, Tucson, AZ. Protein was measured using the BioRad (Bio-Rad Laboratories, Richmond, CA) protein assay. Phospholipids were measured as described by Bartlett (20). Quantitative estimation of visible ${ }^{14} \mathrm{C}$-labeled protein bands on photographic films was performed with a Zenith soft Laser scanner.

\section{RESULTS}

Plasma from warfarin-treated pregnant rats had prothrombin times between 50 and $60 \mathrm{~s}$ which were significantly prolonged compared to prothrombin times in pooled plasma from salinetreated pregnant rats (13-14 s). Rats, 16 to $21 \mathrm{~d}$ pregnant, had shorter prothrombin times than nonpregnant adult rats but prothrombin time normalized shortly after delivery.

Before investigating vitamin $\mathrm{K}$ function and metabolism in fetal liver microsomes, it was necessary to identify these subcellular particles isolated from livers in various stages of development. We chose to investigate the proteins in fetal microsomes as they appear in SDS-PAGE gels after staining with Coomassie brilliant blue. Thus, microsomal proteins from fetal livers were subjected to SDS-PAGE in $10 \%$ reducing gels. As shown in Figure 1, the protein patterns of microsomes from $\mathrm{d} 16,17,18$, 19 , and 20 fetal rats was quite similar, suggesting that the subcellular particles we had isolated indeed were derived from the same cellular organelles. The protein pattern of adult liver microsomes is also shown (Fig. 2, lane $A$ ). As shown, there was a strong degree of similarity between the adult pattern and the fetal pattern. However, some change in the protein pattern occurred at birth (Fig. 2, lane 21) and this change was most apparent in the $M_{r}$ range $45-50 \mathrm{kD}$ where cytochrome $\mathrm{P}-450$ normally migrates in this gel system (21).

These microsomes and also microsomes from 2- and 7-d neonatal rats were used to investigate their ability to carry out vitamin K-dependent $\gamma$-carboxylation of the synthetic pentapeptide Phe-Leu-Glu-Glu-Leu (Fig. 2). To compare the data obtained from livers in various stages of development it was necessary to relate all measurements to a stable parameter. In all microsomal preparations, phospholipid and protein were determined. We found, however, that the phospholipid to protein ratio increased toward birth. Thus, between the microsomal protein and phospholipid concentrations, protein was chosen as the most stable parameter. Therefore all data are expressed per $\mathrm{mg}$ of microsomal protein. In microsomes from fetal rats carboxylase activity increased toward birth (Fig. 2). Changes in activity were most pronounced at birth where the activity in control fetal rats and fetal rats from mothers treated with warfarin had increased 1.4- and 1.6-fold, respectively, over the activity measured in d-20 fetal rats (Fig. $2, A$ and $B$ ). In d-16 fetal rats, pathway II-supported carboxylase activity could not be measured 


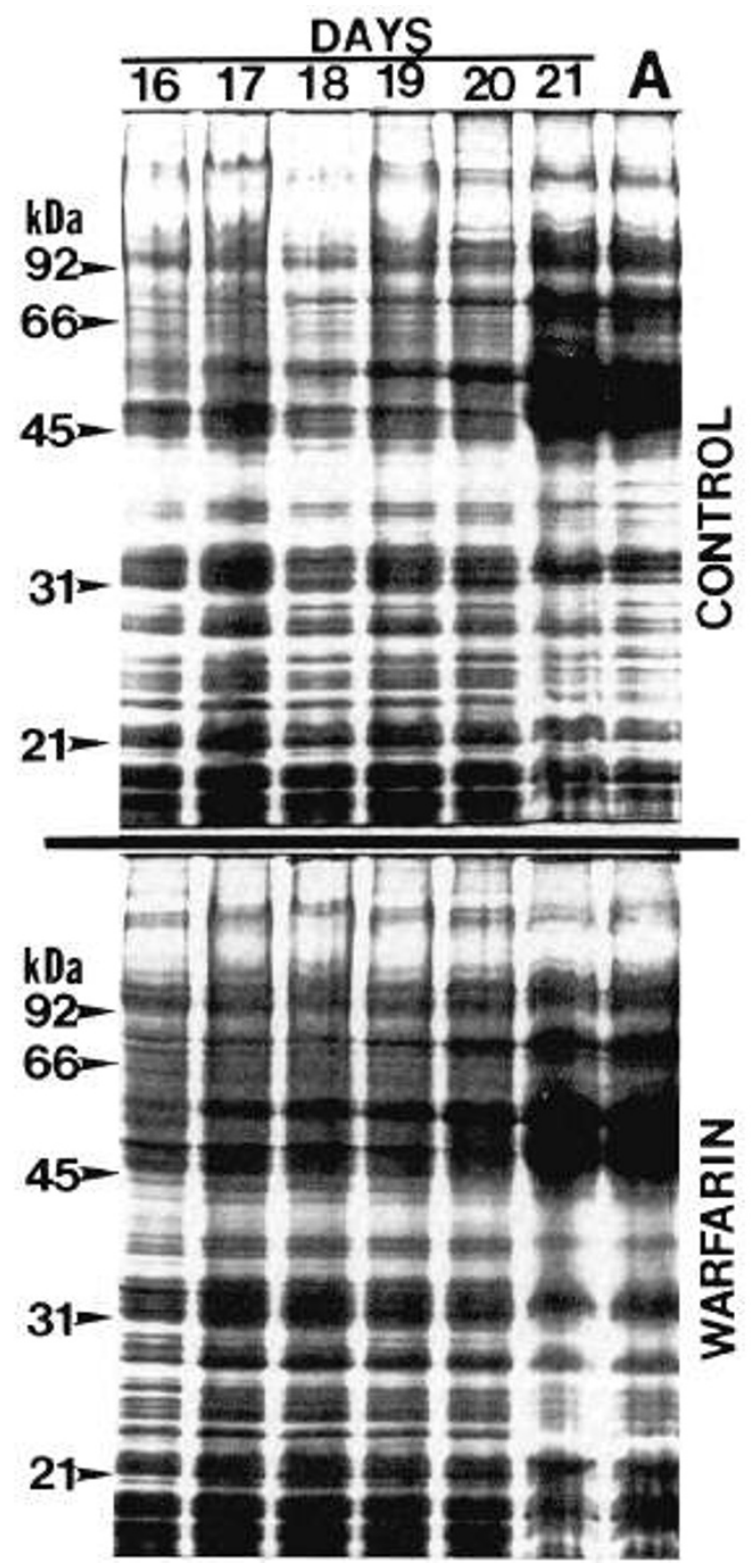

Fig. 1. SDS-PAGE of microsomal proteins from fetal and adult rat livers. Liver microsomes isolated from fetal rats killed on d 16, 17, 18, 19 , and 21 of gestation and from adult rat liver (lane $A$ ) were subjected to SDS-PAGE in $10 \%$ reducing gels. Proteins were stained with Coomassie brilliant blue. The control and the warfarin panels have microsomes from saline and warfarin treated rats respectively (see Materials and Methods). A total of 25 to $40 \mu \mathrm{g}$ of protein was loaded onto the various lanes. The migration of standard proteins with known $M_{\mathrm{r}}(\mathrm{kD})$ is indicated.

by our test system. However, significant activity was measured in d-17 fetal rats and in liver microsomes from more developed rats (Fig. 2). However, significant pathway I-supported carboxylase activity was measured in d-16 fetal rats, which suggests an earlier emergence during development of the pathway I enzyme vitamin $K$ epoxide reductase than the pyridine nucleotide-dependent enzymes catalyzing pathway II. However, these activities were never as high as the activities measured in liver microsomes from the mothers (see Fig. 5).

During development of the fetus from d 16 to 21 (birth) some variation was found in the ability of pathway I and II to provide the carboxylase with reduced vitamin $\mathrm{K}_{1} \mathrm{H}_{2}$ cofactor (Fig. 2). However, when measured relative to the activity of the vitamin $\mathrm{K}$-dependent carboxylase our data showed no specific increase either in pathway I- or pathway II-supported carboxylase activity toward birth. This suggests that the pathway I and II enzymes, during development of the rat fetus, do not emerge at a faster rate than the carboxylase enzyme.

When compared to control rats, pathway I-supported carboxylase activity was inhibited $85 \%$ in microsomes from d-16 fetal livers obtained from mothers that had been injected with warfarin. Inhibition of this activity was also measured in microsomes from more developed warfarin-treated rats (see Fig. 2, inset). However, pathway II-supported carboxylase activity was not affected by warfarin administration to the mother (compare Fig. 2, $A$ and $B$ ).

Carboxylase activity measured in microsomes from 2 -d neonatal rats was reduced $50 \%$ from this activity measured in fetal liver microsomes at birth. This "dip" in activity was observed in control neonatal rats (Fig. $2, A$ ) as well as in neonatal rats treated with $30 \mathrm{mg} / \mathrm{kg}$ of warfarin (Fig. 2, $B$ ). In 7-d neonatal rats the activity had risen to a level that was 2.5 -fold higher than the activity measured in microsomes from the mothers (Fig. 2).

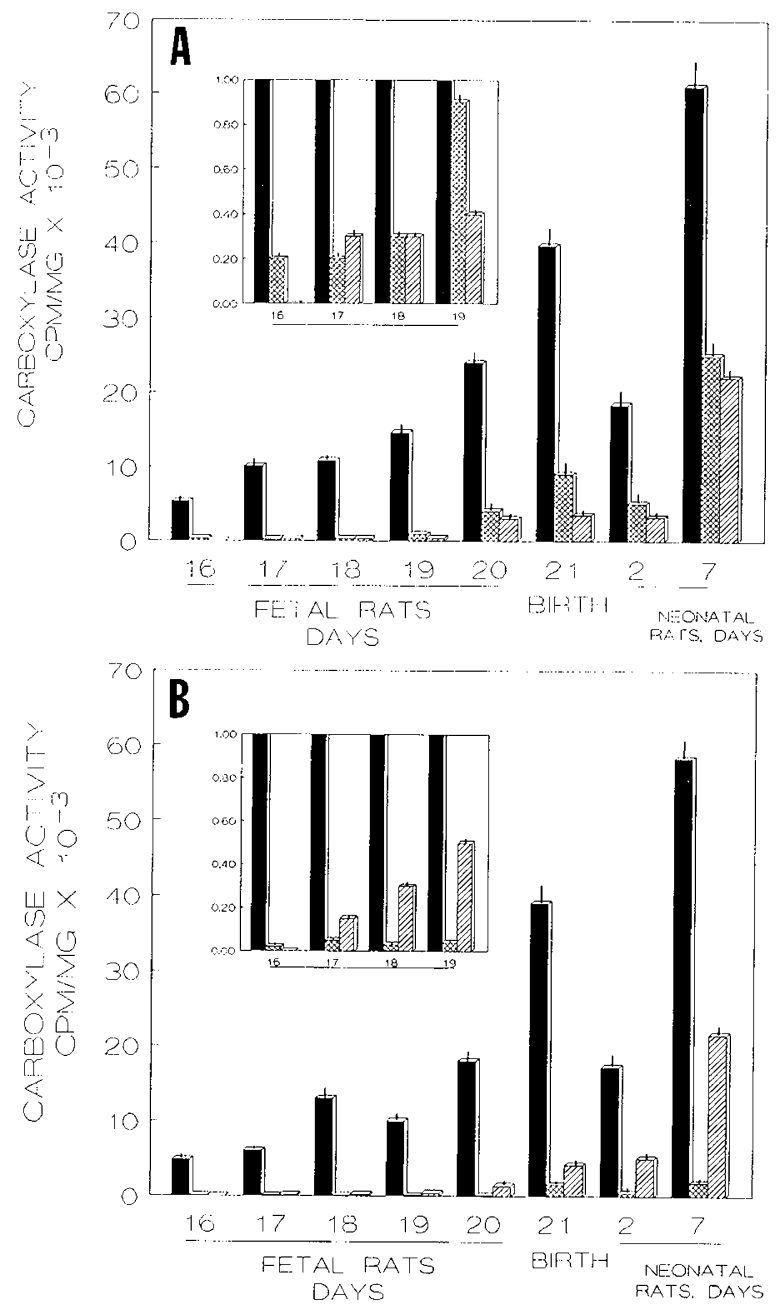

Fig. 2. Vitamin K-dependent carboxylase activity in fetal and neonatal rat liver microsomes. $A$ and $B$ present the activities measured in microsomes from saline and warfarin treated fetal and neonatal rats, respectively. Fetal rats were obtained from saline or warfarin treated mothers (see Materials and Methods). Carboxylase activity was measured as carboxylation of the synthetic pentapeptide Phe-Leu-Glu-Glu-Leu. Carboxylase activity triggered with chemically reduced vitamin $\mathrm{K}_{1} \mathrm{H}_{2}$ (solid bars) and when supported by pathway I (DTT + vitamin $\mathrm{K}_{1}$ ) (cross-hatched bars) and by pathway II (NADH + vitamin $\mathrm{K}_{1}$ ) (diagonal bars) is shown (see Materials and Methods). Standard deviations are shown as vertical lines $(n=3)$. Insets are magnifications that cover the data from d 16 through 19. 


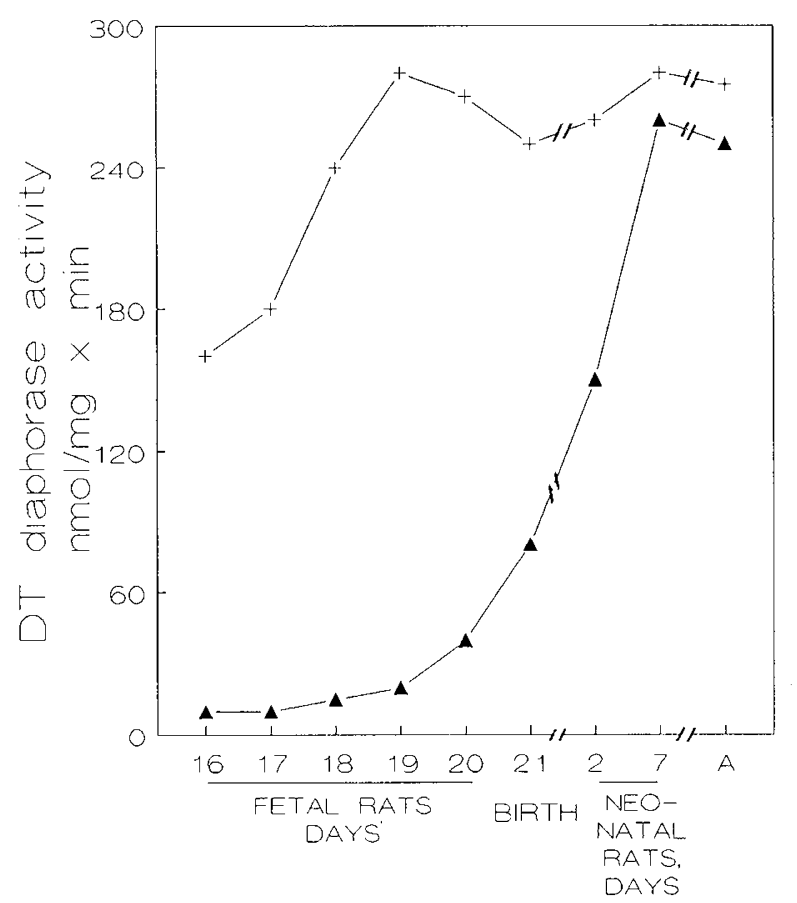

Fig. 3. DT diaphorase activity in liver and lung cytosol from fetal and neonatal rats. DT diaphorase activity was measured in lung (x) and liver $(\triangle)$ cytosol obtained from pooled fetal and neonatal rats. Enzyme activity was measured as reduction of the dye 2,6-dichlorophenol indophenol. The activity measured in liver and lung cytosol from normal adult rats is shown ( $A$, adult).

In 2- and 7-d neonatal rats pathway II was clearly more active than at birth (Fig. $2 A$ ). This apparent delay of the pathway II enzymes in development was supported by the finding of a late appearance in liver of one of the enzymes (DT-diaphorase) catalyzing this pathway (11).

As shown in Figure 3, DT-diaphorase (EC.1.6.99.2) activity is low in fetal livers. The activity increased in neonatal livers and had reached adult levels in 7-d neonates. Interestingly, this activity in fetal lung had reached adult levels already on $\mathrm{d} 17$ of gestation (Fig. 3). Thus, during development of the rat, the timing of emergence of this enzyme in lung and liver is quite different. However, the warfarin-sensitive pathway I enzyme, the vitamin $\mathrm{K}$ epoxide reductase, revealed significant activity in liver microsomes from d-16 fetal rats. Figure 4 shows this activity when measured in liver microsomes from fetal and neonatal livers (Fig. $4 A$ ) and in livers from the mothers (Fig. $4 B$ ), respectively. Also shown in Figure 4 is the significantly lower vitamin $\mathrm{K}$ epoxide reductase activity measured in liver microsomes from warfarintreated rats.

There was very little variation in the activities of the vitamin $\mathrm{K}$-dependent carboxylation system in maternal livers before and after birth (Fig. 5). As shown by inhibition of pathway I-supported carboxylase activity, warfarin had also affected the vitamin $\mathrm{K}$-dependent carboxylation system in maternal livers (compare $A$ and $B$ in Fig. 5).

Carboxylation of endogenous microsomal protein (protein carboxylation) was also measured in fetal and neonatal liver microsomes (Fig. 6). This activity that reflects carboxylation of the natural substrates for the vitamin K-dependent carboxylase, was enhanced about 1 -fold in fetal liver microsomes from warfarin-treated mothers that again indicates an effect of warfarin on the fetus (10).

The prothrombin precursor concentration in fetal liver microsomes increased toward birth and there was a marked increase in the concentration at birth (Fig. $7 A$ ). Fetal and neonatal liver microsomes from warfarin-treated mothers had higher pro-
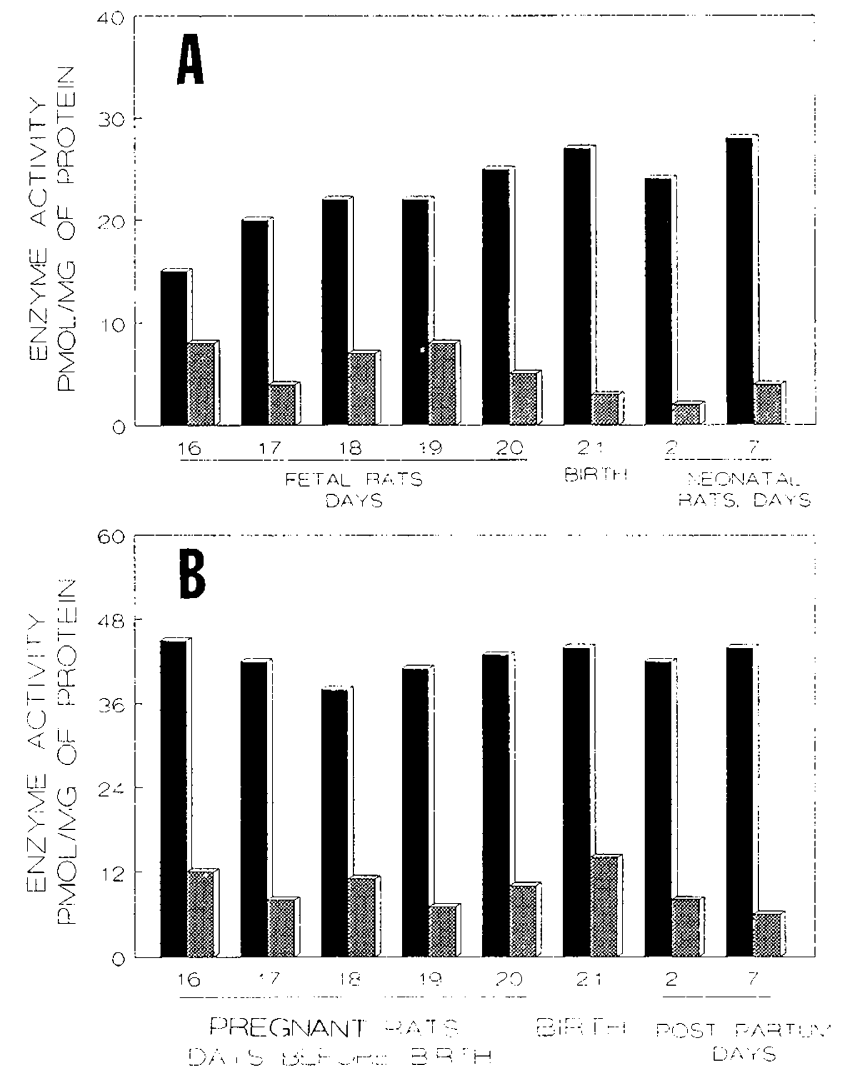

Fig. 4. Vitamin $\mathrm{K}$ epoxide reductase activity in fetal, neonatal, and maternal livers. Vitamin $\mathrm{K}$ epoxide reductase activity was measured in liver microsomes from fetal and neonatal rats (panel $A$ ) killed on the days indicated in the figure (see legend to Fig. 3). Panel $B$ presents this activity in microsomes isolated from maternal livers. The bars are the average activity of three independent measurements. The activity was measured as described in Materials and Methods as pmol vitamin $\mathrm{K}_{1}$ reduced from vitamin $K_{1}$ 2,3-epoxide. The activity in saline treated rats (solid bars) and in warfarin treated rats (cross-hatched bars) is shown.

thrombin precursor concentrations than microsomes prepared from saline-treated mothers (Fig. $7 A$ ). Liver microsomes from pregnant and postpartum adult rats treated with warfarin revealed a 2.5 - to 3 -fold increase in the prothrombin precursor concentration over control rats treated with saline (Fig. $7 B$ ). In these adult rats we measured a transient increase in the prothrombin precursor concentration around the time of birth but this increase was small compared to the increase measured in fetal liver microsomes at birth (compare Fig. 7, $A$ and $B$ ).

Recently we presented evidence that vitamin K-dependent ${ }^{14} \mathrm{C}$-labeling of a $70-\mathrm{kD}$ microsomal protein in vitro is a marker for the effect of warfarin on the liver in vivo. The protein was identified as the factor $\mathrm{X}$ carboxylase substrate (17). We used this test to evaluate the response of the fetal liver to this drug when administered to the mother. As a control, we used the test on liver microsomes isolated from pregnant rats. Indeed, liver microsomes isolated from pregnant rats treated with warfarin revealed, in addition to the $78-\mathrm{kD}$ prothrombin precursor (17) and some other faintly ${ }^{14} \mathrm{C}$-labeled proteins, the heavily ${ }^{14} \mathrm{C}$ labeled 70-kD protein (Fig. 8, lane $W$ ). In fetal liver microsomes from both warfarin- (Fig. 9, panel $W$ ) and saline- (Fig. 9, panel $S$ ) treated mothers, ${ }^{14} \mathrm{C}$-labeling of the $78-\mathrm{kD}$ prothrombin precursor was seen from d 16 of gestation. However, ${ }^{14} \mathrm{C}$-labeling of the $70-\mathrm{kD}$ protein was clearly visible only in microsomes prepared from fetal livers from warfarin-treated mothers (Fig. 9, panel $W$ ). This experiment strongly suggest that warfarin affects the fetal liver by a mechanism that is similar to its mechanism of action in the mother. 

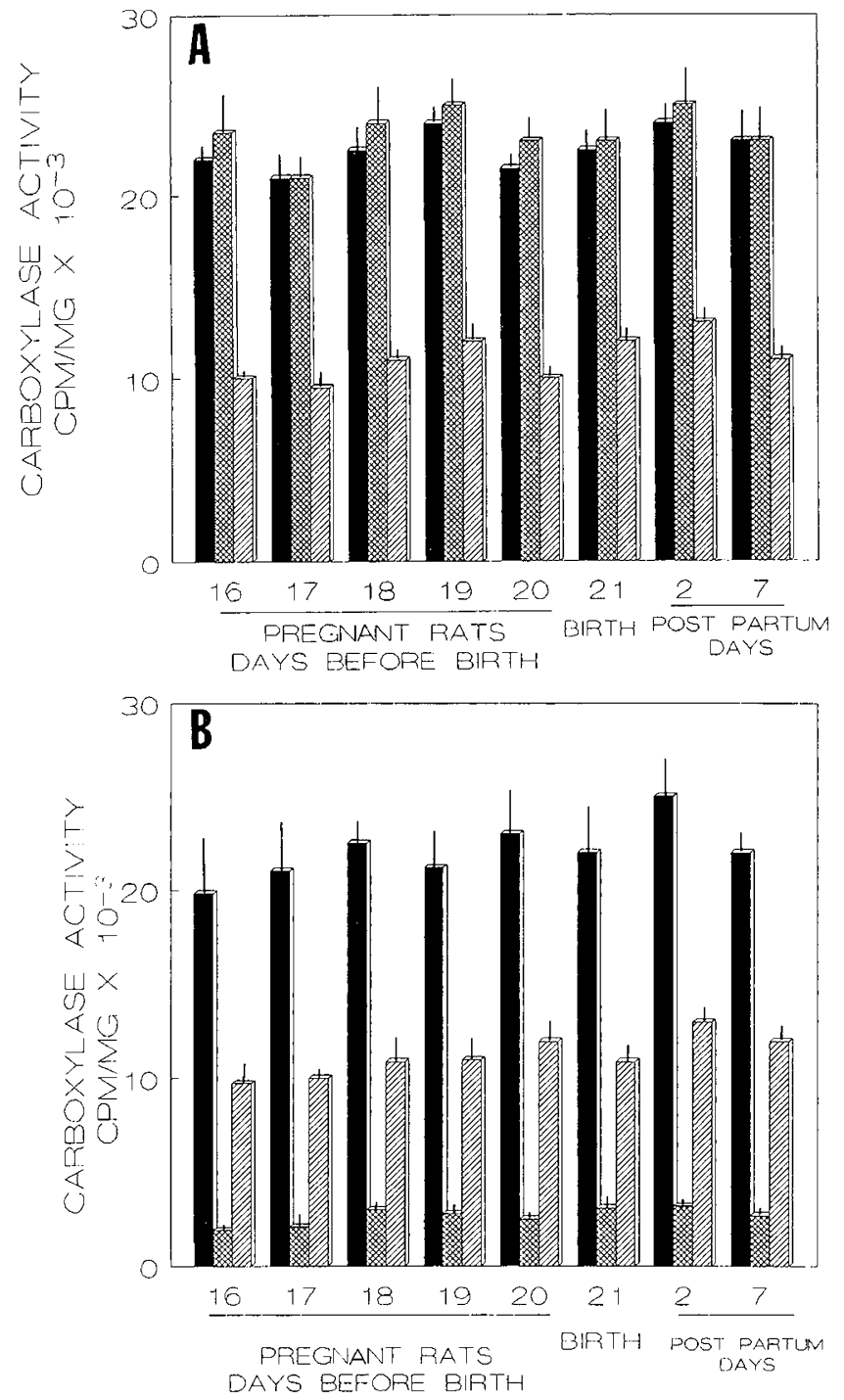

Fig. 5. Vitamin K-dependent carboxylase activity in maternal liver. Carboxylase activity triggered with chemically reduced vitamin $\mathrm{K}_{1} \mathrm{H}_{2}$ (solid bars) and when supported by pathway I (cross-hatched bars) and pathway II (diagonal bars) is shown (see legend to Fig. 3). $A$ and $B$ present data from time pregnant rats treated with saline and warfarin, respectively. SD are shown as vertical lines $(n=3)$.

\section{DISCUSSION}

Our report presents evidence for a maturation process of the vitamin $\mathrm{K}$-dependent carboxylation system in the developing rat. The data demonstrate that coumarin anticoagulant drugs, when administered to the mother, affect the fetal liver by a mechanism that is similar to its mechanism of action in the adult liver. Clearly, warfarin reached the liver in $\mathrm{d}-16$ fetuses and inhibited vitamin $\mathrm{K}$ epoxide reductase, the coumarin-sensitive enzyme of the vitamin $\mathrm{K}$ cycle (10). Warfarin also induced the appearance of the $70-\mathrm{kD}$ vitamin $\mathrm{K}$-dependent protein that has been shown previously (17) to be a marker for the effect of this drug on the liver.

In d-16 fetal livers pathway II-supported carboxylase activity could not be detected by our test system. Pathway II, which is responsible for the antidotal effect of vitamin $\mathrm{K}$ (11), started to emerge in $\mathrm{d}-17$ fetal livers. These data suggest that the rat fetus, until d 16 of gestation, is more vulnerable to coumarin intoxication than more developed rats. Reversal of the anticoagulant effect of coumarin drugs by pathway II would depend, of course, on whether or not enough vitamin $\mathrm{K}$ can reach the fetal liver to

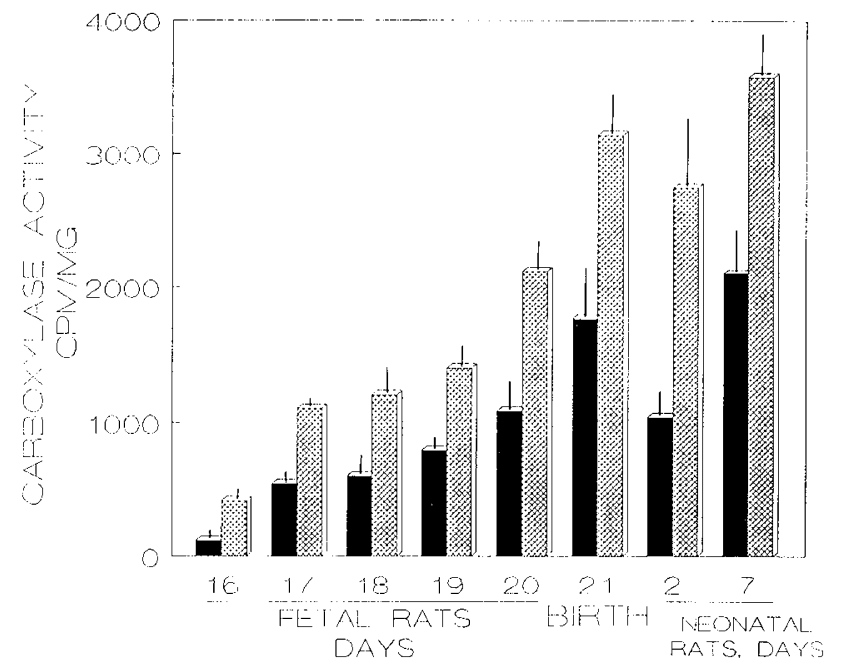

Fig. 6. Vitamin K-dependent carboxylation of protein in liver microsomes from fetal and neonatal rats. Carboxylation of endogenous proteins in liver microsomes (protein carboxylation) was measured as described in Materials and Methods using chemically reduced vitamin $\mathrm{K}_{1} \mathrm{H}_{2}$ to trigger the reaction. The activities shown are from rats treated with saline (solid bars) and warfarin (cross-hatched bars). SD are shown as vertical lines $(n=3)$.
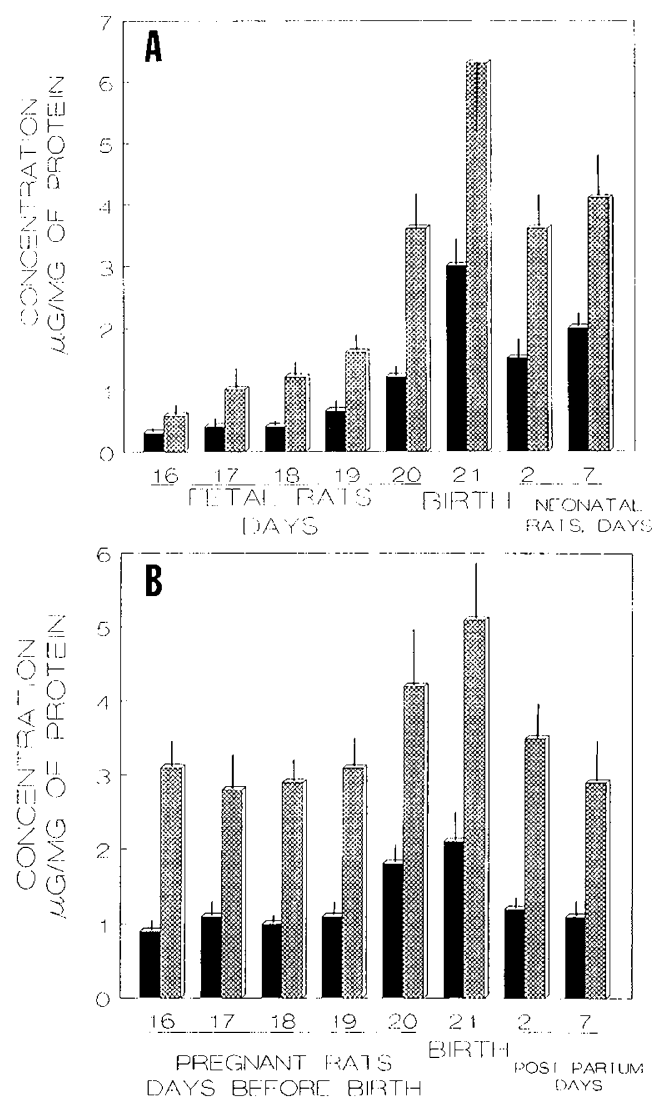

Fig. 7. Prothrombin precursor concentration in microsomes from fetal, neonatal, and maternal livers. An immunodot blot assay was used for detection of the prothrombin antigen in microsomes solubilized with the detergent Triton-X-100. Quantitative estimation of the antigen concentration was achieved with ${ }^{125} \mathrm{I}$-protein A (see Materials and Methods). The concentrations shown are from saline-treated rats (solid bars) and from warfarin-treated rats (cross-hatched bars). Panels $A$ and $B$ present the data from fetal/neonatal and maternal rats, respectively. Standard deviations are shown as vertical lines $(n=3)$. 


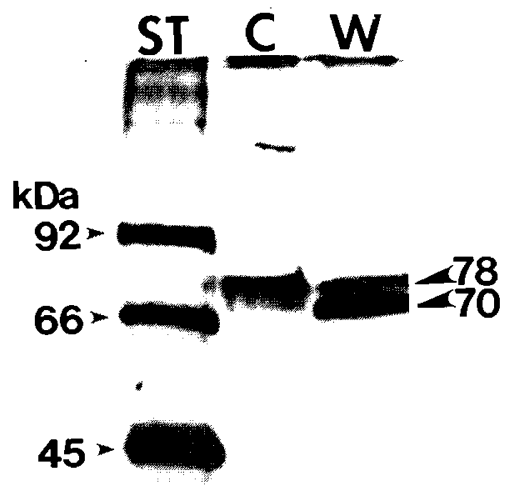

$31 \times$

In 2-d neonatal rats, peptide carboxylase activity dropped to $50 \%$ of the activity measured at birth. This "dip" in activity found in 2-d neonatal rats coincided with a similar dip for protein carboxylase activity and a lower prothrombin precursor concentration in livers from these rats. Later experiments with pooled livers from other rat litters have shown that the "dip" can vary, but a dramatic increase in carboxylase activity around $\mathrm{d} 7$ is always found. From studies with rat liver microsomes it has been shown that changes in peptide and protein carboxylation as well as the prothrombin precursor concentration follow the same pattern (24). Thus, all the parameters measured do indeed suggest that a less efficient carboxylation system exists shortly after birth. The data are interesting in that human neonates often have a prolonged prothrombin time $2-3$ days after birth $(25,26)$. This physiologic dip has been considered to be a combination of vitamin $\mathrm{K}$ deficiency and hepatic immaturity (25). Inasmuch as PIVKA factors (Proteins Induced in Vitamin $K A$ bsence) (27) rarely are found in neonatal blood, a vitamin $\mathrm{K}$ deficiency seems unlikely to be responsible for this phenomenon. Our data from the rat support the hypothesis of an immature vitamin $\mathrm{K}$ dependent carboxylation system, which for unknown reasons, is down-regulated transitionally shortly after birth.

In the fetus, peptide and protein carboxylase activities and also the liver prothrombin precursor concentration peaked around birth. Although there was no significant change in carboxylase activity in the mothers, the prothrombin precursor concentration revealed a transient increase at that time. Inasmuch as the appearance of many enzymes in the developing liver has been shown (28) to be closely related to changes in the hormonal environment, these data are interesting in light of the profound hormonal changes that occur around birth (28). Our data may indeed reflect hormonal control of maturation of the vitamin $\mathrm{K}$ dependent carboxylation system. Such control can be exerted at the level of gene expression as well as at other sites along the biosynthetic route for these proteins. Whether or not maturation of the vitamin $\mathrm{K}$-dependent carboxylation system is regulated by gene expression cannot be decided before the enzymes that constitute this system have been purified and cDNA probes are made available.

In developing tissues and organs specific enzymes are known to be expressed on time schedules, and these enzymes enable the growing organism to cope with the demands of fetal life and life after separation from the maternal environment. In premature neonates, normal development is interrupted. Such interruption may result in a hemostatic system where imbalances can occur easier, and this may be responsible for the more frequent bleeding complications experienced with premature neonates.

\section{REFERENCES}

Fitamin $\mathrm{K}$-dependent microsomal proteins in fetal livers. ${ }^{14} \mathrm{C}$-labeled vitamin $\mathrm{K}$-dependent proteins from d $16,17,18$,
19,20 , and 21 fetal livers were subjected to SDS-PAGE and fluorography. $C$ and $W$ have the proteins from saline treated and warfarin treated rats, respectively. Each lane has $25-30 \mu \mathrm{g}$ of protein. The positions in the gel of the $78-\mathrm{kD}$ prothrombin precursor and the $70-\mathrm{kD}$ protein are indicated with arrows.

trigger-reduced vitamin $\mathrm{K}_{1} \mathrm{H}_{2}$ cofactor production by pathway II. Inasmuch as the extent of placental transport of vitamin $\mathrm{K}_{1}$ is still controversial $(22,23)$ this question remains unanswered.

Pathway II was clearly more active after birth in providing the carboxylase with reduced vitamin $\mathrm{K}_{1} \mathrm{H}_{2}$ cofactor. The idea of a more active pathway II after birth was supported by the finding of a late emergence of the pathway II enzyme, DT diaphorase, (11) in the developing liver. Shortly after birth, this activity increased dramatically. Because DT diaphorase is a vitamin Kreducing enzyme belonging to reduction pathway II of the vitamin K-dependent carboxylation system (11), these data support our hypothesis that vitamin $\mathrm{K}$ would be more active as an antidote to overcome coumarin anticoagulant poisoning in neonates than in the fetus.

1. Buchanan GR 1986 Coagulation disorders in the neonate. Pediatr Clin North Am 33:203-220

2. Andrew M, Paes B, Milner R, Johnston M, Mitchell L, Tollefsen DM, Powers P 1987 Development of the human coagulation system in the full-term infant. Blood 70:165-172

3. Fujimura Y, Mimura Y, Kinoshita S, Yoshioka A, Kitawaki T, Yoshioka K, Takamiya O 1982 Studies on vitamin K-dependent factor deficiency during early childhood with special reference to prothrombin activity. Haemostasis 11:90-95

4. Lane PA, Hathaway WE 1985 Vitamin K in infancy. J Pediatr 106:351-359

5. Terwiel JP, Veltkamp JJ, Bertina RM, Van Der Linden IK, Van Tilburg NH 1985 Coagulation factors in the premature infant born after about 32 weeks of gestation. Biol Neonate 47:9-18

6. Bernard DR, Simmons MA, Hathaway WE 1979 Coagulation studies in extremely premature infants. Pediat Res 13:1330-1335

7. Kisker CT, Perlman S, Bohlken D, Wicklund B 1988 Measurements of prothrombin mRNA during gestation and early neonatal development. J Lab Clin Med 1 12:407-412

8. Hassan HJ, Leonard A, Chelucci C, Guerriero R, Mannucci PM, Peschle C 1987 Expression in ontogenesis of human blood coagulation factors. Thromb Haemost 58:490(abstr)

9. Wallin R, Martin LF 1985 Vitamin K-dependent carboxylation and vitamin $\mathrm{K}$ metabolism in liver: effects of warfarin. J Clin Invest 76:1879-1884

10. Suttie JW 1985 Vitamin K-dependent carboxylase. Annu Rev Biochem 54:459-477 
11. Wallin R, Martin LF 1987 Warfarin poisoning and vitamin K metabolism in rat and human liver. Design of a system in vitro that mimics the situation in vivo. Biochem J 241:389-396

12. Fasco MJ, Principe LM $1982 \mathrm{R}$ - and S- warfarin inhibition of vitamin K and vitamin K 2,3-epoxide reductase activities in the rat. J Biol Chem 257:48944901

13. Wallin R, Patrick SD, Ballard JO 1986 Vitamin K antagonism of coumarin intoxication in the rat. Thromb Haemost 55:235-239

14. Esmon CT, Suttie JW 1976 Vitamin K-dependent carboxylase. Solubilization and properties. J Biol Chem 251:6238-6243

15. Martin LF, Patrick SD, Wallin R 1987 DT-diaphorase in morbidly obese patients. Cancer Lett 36:341-347

16. Reiderer BM, Zagon IS, Goodman SR 1987 Brain spectrin (240/235) and brain spectrin $(240 / 235 \mathrm{E})$ : differential expression during mouse brain development. J Neurosci 7:864-874

17. Wallin R, Martin LF 1988 Early processing of prothrombin and factor X by the vitamin K-dependent carboxylase. J Biol Chem 263:9994-10001

18. Laemmli UV 1970 Cleavage of structured proteins during the assembly of the head of bacteriophage TL. Nature 227:680-685

19. Sadowski JA, Esmon CT, Suttie JW 1976 Vitamin K-dependent carboxylase. Requirements of the rat liver microsomal enzyme system. J Biol Chem 251:2770-2776
20. Bartlett GR 1958 Phosphorus assay in column chromatography. J Biol Chem 234:466-468

21. Lu AYH, West SB 1980 Multiplicity of mammalian microsomal cytochromes P-450. Pharmacol Rev 31:277-295

22. Sann L, Leclercq M, Troncy J, Guillaumond M, Berland M, Coeur P 1985 Serum vitamin $K_{1}$ concentration and vitamin $K$-dependent clotting factor activity in maternal and fetal cord blood. Am J Obstet Gynecol 153:771774

23. Kries RV, Shearer MJ, Göbel U 1988 Vitamin K in infancy. Eur J Pediatr 147:106-112

24. Suttie JW 1978 Vitamin K. In: Decluca HF (ed) The Fat Soluble Vitamins, Handbook of Lipid Research, Vol 2. Plenum Press, New York, pp 211-277

25. Aballi AJ, De Lamerens S 1962 Coagulation changes in the neonatal period and in early infancy. Pediatr Clin North Am 9:785-817

26. Dube B, Dube RK, Bhargava V, Kolindewala JK, Kota VLN, Das BK 1986 Hemostatic parameters in new born. I. Effect of gestation and rate of intrauterine growth. Thromb Haemost 55:47-50

27. Shapiro AD, Jacobson LJ, Armon ME, Manco-Johnson MJ, Hulac P, Lane PA, Hathaway WE 1986 Vitamin $\mathrm{K}$ deficiency in the newborn infant: prevalence and perinatal risk factors. J Pediatr 109:675-680

28. Bohme HJ, Sparmann G, Hofmann E 1983 Biochemistry of liver development in the perinatal period. Experientia 39:473-483

\section{Announcement}

\section{Pediatric Critical Care Medicine Examination}

The Sub-board of Pediatric Critical Care Medicine of the American Board of Pediatrics will administer its next certifying examination on Friday, July 20, 1990 .

The following criteria must be met to be eligible to sit for the examination: 1 . Certification by the American Board of Pediatrics. 2 . Subspecialty Training or Experience. Three years of full-time subspecialty residency training in pediatric critical care medicine is required of those physicians entering training on or after January 1, 1988. Physicians who entered training prior to January 1, 1988, may apply for admission on the basis of their completion of two years of training in pediatric critical care medicine. No foreign training will be accepted. OR Certification in pediatric cardiology, neonatal-perinatal medicine, pediatric pulmonology, or anesthesiology based on completion of the full-time residency training requirements plus two years of training in pediatric critical care medicine. Physicians who entered training in pediatric critical care medicine prior to January 1, 1988, will need only one year of training. $O R$ Five years of broadly based pediatric critical care medicine. A minimum of $50 \%$ of full-time professional activities must be spent in pediatric critical care medicine to receive credit. These five years should be of such type and quality that they substitute for the clinical exposure one might have encountered during subspecialty training. All pediatric critical care medicine experience must be accrued before December 31,1991 . $O R$ a) Those applicants who completed less than 12 months of subspecialty residency training in pediatric critical care medicine may receive credit on a month-for-month basis. b) Those applicants completing 12 to 23 months of subspecialty residency training in pediatric critical care medicine may receive credit on a two-for-one basis. The above credit added to practice experience must total 60 months or five years. These five years must be accrued prior to December 31,1991 . NO CREDIT FOR PARTIAL TRAINING WILL BE GIVEN FOR SUBSPECIALTY RESIDENTS WHO BEGAN THEIR TRAINING AFTER JANUARY 1, 1988. 3. Verification of training and recommendation by Program Director.

Each application will be considered individually and must be acceptable to the Sub-board of Pediatric Critical Care Medicine. Registration will extend from SEPTEMBER 1, 1989 to NOVEMBER 30, 1989. Requests for applications received prior to September 1, 1989, will be held on file. The application fee for the examination is $\$ 1000$, but applications postmarked after NOVEMBER 30, 1989, must include an additional \$200 late fee. NEW APPLICATIONS POSTMARKED AFTER DECEMBER 30, 1989, CANNOT BE ACCEPTED FOR THE 1990 EXAMINATION. Please direct inquiries to the American Board of Pediatrics, 111 Silver Cedar Court, Chapel Hill, NC 27514-1651. Telephone: (919) 929-0461. 